\title{
Identification of the interstitial Mn site in ferromagnetic (Ga,Mn)As
}

T. A. L. Lima, ${ }^{1}$ U. Wahl, ${ }^{2}$ V. Augustyns, ${ }^{1}$ D. J. Silva, ${ }^{3}$ A. Costa, ${ }^{2}$ K. Houben, ${ }^{4}$ K. W. Edmonds, ${ }^{5}$ B. L. Gallagher, ${ }^{5}$ R. P. Campion, ${ }^{5}$ M. J. Van Bael, ${ }^{4}$ M. R. da Silva, ${ }^{6}$ J. G. Correia, ${ }^{2}$ J. P. Araújo, ${ }^{3}$ K. Temst, ${ }^{1}$ A. Vantomme, ${ }^{1}$ and L. M. C. Pereira $1,{ }^{\text {a }}$

${ }^{1}$ KU Leuven, Instituut voor Kern- en Stralingsfysica, 3001 Leuven, Belgium

${ }^{2}$ Centro de Ciências e Tecnologias Nucleares, Instituto Superior Técnico, Universidade de Lisboa, 2686-953 Sacavém, Portugal

${ }_{3}^{3}$ IFIMUP and IN-Institute of Nanoscience and Nanotechnology, Universidade do Porto, 4169-007 Porto, Portugal

${ }^{4}$ Laboratory of Solid-State Physics and Magnetism, KU Leuven, 3001 Leuven, Belgium

${ }^{5}$ School of Physics and Astronomy, University of Nottingham, Nottingham NG7 2RD, United Kingdom

${ }^{6}$ Centro de F isica Nuclear, Universidade de Lisboa, Lisboa 1649-003, Portugal

(Received 28 November 2014; accepted 23 December 2014; published online 6 January 2015)

We determined the lattice location of $\mathrm{Mn}$ in ferromagnetic $(\mathrm{Ga}, \mathrm{Mn}) \mathrm{As}$ using the electron emission channeling technique. We show that interstitial Mn occupies the tetrahedral site with As nearest neighbors $\left(\mathrm{T}_{\mathrm{As}}\right)$ both before and after thermal annealing at $200{ }^{\circ} \mathrm{C}$, whereas the occupancy of the tetrahedral site with Ga nearest neighbors $\left(\mathrm{T}_{\mathrm{Ga}}\right)$ is negligible. $\mathrm{T}_{\mathrm{As}}$ is therefore the energetically favorable site for interstitial $\mathrm{Mn}$ in isolated form as well as when forming complexes with substitutional $\mathrm{Mn}$. These results shed new light on the long standing controversy regarding $\mathrm{T}_{\mathrm{As}}$ versus $\mathrm{T}_{\mathrm{Ga}}$ occupancy of interstitial $\mathrm{Mn}$ in $(\mathrm{Ga}, \mathrm{Mn})$ As.

[http://dx.doi.org/10.1063/1.4905556]

(Ga,Mn)As has become the model system, in which to explore the physics of carrier-mediated ferromagnetism in semiconductors and the associated spintronic phenomena. ${ }^{1,2}$ In particular, as the most widely studied dilute magnetic semiconductor (DMS), $(\mathrm{Ga}, \mathrm{Mn})$ As is the perfect example of how the magnetic behavior of DMS materials is strongly influenced by local structure. In typical high Curie temperature $\left(T_{\mathrm{C}}\right)(\mathrm{Ga}, \mathrm{Mn}) \mathrm{As}$ thin films (several \% Mn regime), the majority of the $\mathrm{Mn}$ atoms substitute for $\mathrm{Ga}$ $\left(\mathrm{Mn}_{s}\right)$, while a minority fraction (several \% of all $\mathrm{Mn}$ ) occupies interstitial sites $\left(\mathrm{Mn}_{i}\right){ }^{3,4} \mathrm{Mn}_{s}$ provides both the localized magnetic moment and the itinerant hole that mediates the magnetic coupling, whereas $\mathrm{Mn}_{i}$ has a twofold compensating effect: (i) magnetically, as $\mathrm{Mn}_{i}-\mathrm{Mn}_{s}$ pairs couple antiferromagnetically and (ii) electrically, since double donor $\mathrm{Mn}_{i}$ compensates $\mathrm{Mn}_{s}$ acceptors. ${ }^{3}$ For a given $\mathrm{Mn}_{s}$ concentration, $\mathrm{Mn}_{i}$ therefore determines the hole concentration, the Fermi level and the effective $\mathrm{Mn}_{s}$ concentration (of non-compensated $\mathrm{Mn}_{s}$ moments), all of which define the magneto-electronic behavior of $(\mathrm{Ga}, \mathrm{Mn})$ As. The existence of such a crucial role of $\mathrm{Mn}_{i}$ is clearly reflected in the effect of the $\mathrm{Mn}_{i}$ concentration on the two relevant figures of merit: $T_{\mathrm{C}}$ and magnetization. ${ }^{3-5}$

Despite this central role in the understanding of (Ga,Mn)As, and, consequently, of Mn-doped III-V DMS materials, interstitial $\mathrm{Mn}$ is far from being a well understood defect. The presence of $\mathrm{Mn}_{i}$ in ferromagnetic $(\mathrm{Ga}, \mathrm{Mn}) \mathrm{As}$ was first reported based on ion channeling measurements. ${ }^{6}$ Although consistent with $\mathrm{Mn}_{i}$ occupying tetrahedral (T) interstitial sites, the measurements did not allow to discriminate between the two nonequivalent $\mathrm{T}$ sites: coordinated by four $\mathrm{Ga}$ atoms $\left(\mathrm{T}_{\mathrm{Ga}}\right)$ or by four As atoms $\left(\mathrm{T}_{\mathrm{As}}\right)$. Transmission electron microscopy measurements using the (002) diffracted beam indicated that $\mathrm{Mn}_{i}$ predominantly occupies the $\mathrm{T}_{\mathrm{As}}$ site. ${ }^{7} \mathrm{X}$-ray absorption fine structure (XAFS) techniques were later applied, suggesting
$\mathrm{T}_{\mathrm{Ga}}$ occupancy (e.g., Refs. 8 and 9). However, XAFS is not well suited to distinguish neighboring elements with similar atomic numbers, as is the case for Ga and As, especially in such cases of multi-site occupancy (substitutional and interstitial), where the site to be identified is in fact the minority one (interstitial). In pioneering work, using X-ray scattering techniques to probe dopant lattice location, comparable $\mathrm{T}_{\mathrm{Ga}}$ and $\mathrm{T}_{\mathrm{As}}$ occupancies have been reported. ${ }^{10-12}$ Coexisting $\mathrm{T}_{\mathrm{Ga}}$ and $\mathrm{T}_{\mathrm{As}}$ occupancies would suggest that the $\mathrm{Mn}_{i}$ lattice site depends on the presence of neighboring $\mathrm{Mn}_{s}$ atoms, i.e., that isolated $\mathrm{Mn}_{i}$ and $\mathrm{Mn}_{i}$ in $\mathrm{Mn}_{i}-\mathrm{Mn}_{s}$ pairs occupy different $\mathrm{T}$ sites. This is however in contradiction with density functional theory (DFT) calculations which predicted that for typical ferromagnetic $(\mathrm{Ga}, \mathrm{Mn})$ As samples (where the $\mathrm{Mn}_{s}$ concentration is significantly larger than that of $\left.\mathrm{Mn}_{i}\right), \mathrm{T}_{\mathrm{As}}$ is the most stable site for $\mathrm{Mn}_{i}$ regardless of being isolated, in $\mathrm{Mn}_{i}-\mathrm{Mn}_{s}$ pairs, or even in $\mathrm{Mn}_{s}-\mathrm{Mn}_{i}-\mathrm{Mn}_{s}$ triplets. ${ }^{13}$ Solving this inconsistency would allow for a better understanding of the mechanisms of electric and magnetic compensation by $\mathrm{Mn}_{i}$ which, as introduced above, plays a central role in the behavior of $(\mathrm{Ga}, \mathrm{Mn})$ As.

Using the emission channeling (EC) technique, we show here that interstitial $\mathrm{Mn}$ occupies only $\mathrm{T}_{\mathrm{As}}$ sites in ferromagnetic, high Curie temperature $(\mathrm{Ga}, \mathrm{Mn}) \mathrm{As}$ thin films. The EC technique makes use of the charged particles emitted by a decaying radioactive isotope. The screened Coulomb potential of atomic rows and planes determines the anisotropic scattering of the particles emitted isotropically during decay. Along low-index crystal directions of single crystals, this anisotropic scattering results in well-defined channeling or blocking effects. Because these effects strongly depend on a) the initial position of the emitted particles, they lead to emission patterns which are characteristic of the lattice sites occupied by the emitting probe atoms. We have previously applied

${ }^{a}$ lino.pereira@fys.kuleuven.be 
the EC technique to determine the lattice location of $\mathrm{Mn}$ in GaAs in the ultra-low doping regime $(<0.05 \% \mathrm{Mn}){ }^{14,15}$ With emission channeling, the unambiguous distinction between $T_{\mathrm{Ga}}$ versus $\mathrm{T}_{\mathrm{As}}$ sites in the GaAs (zincblende) lattice is a direct structural consequence of the mirrorasymmetry of selected crystal axis (typically $<211>$ or $<110>)^{15}$

We report on two separate experiments on the lattice location of radioactive ${ }^{56} \mathrm{Mn}$ (half-life $t_{1 / 2}=2.56 \mathrm{~h}$ ) implanted into $(\mathrm{Ga}, \mathrm{Mn})$ As thin films grown by molecular beam epitaxy (MBE) ${ }^{16}$ Experiment A consisted of implanting a $\mathrm{Ga}_{0.94} \mathrm{Mn}_{0.06}$ As thin film (25 nm thick, grown directly onto the GaAs substrate) with ${ }^{56} \mathrm{Mn}$ to a fluence of $2 \times 10^{12} \mathrm{~cm}^{-2}$, at an energy of $40 \mathrm{keV}$, and a beam angle of $60^{\circ}$ with respect to the surface normal. The high implantation angle was chosen in order to maximize the fraction of ${ }^{56} \mathrm{Mn}$ probes implanted in the $(\mathrm{Ga}, \mathrm{Mn}) \mathrm{As}$ thin film. The nearGaussian depth profile, simulated using SRIM-2008 (Ref. 17), is characterized by a peak concentration of $6.2 \times 10^{17} \mathrm{~cm}^{-3}(\approx 0.003$ at. \%, i.e., negligible increase in $\mathrm{Mn}$ concentration), a projected range (average depth) of $17 \mathrm{~nm}$ and a straggling of $11 \mathrm{~nm}$, with an estimated $<27 \%$ of the ${ }^{56} \mathrm{Mn}$ probes implanted into the GaAs substrate. Experiment B consisted of implanting a $\mathrm{Ga}_{0.95} \mathrm{Mn}_{0.05} \mathrm{As}$ thin film (200 nm thick, grown onto a $200 \mathrm{~nm}$ AlAs buffer layer, on a GaAs substrate) with ${ }^{56} \mathrm{Mn}$ to a fluence of $7 \times 10^{12} \mathrm{~cm}^{-2}$, with an energy of $30 \mathrm{keV}$ and an angle of $17^{\circ}$ (resulting in a peak concentration of $2.4 \times 10^{18} \mathrm{~cm}^{-3}$, a projected range of $21 \mathrm{~nm}$ and a straggling of $11 \mathrm{~nm}$, i.e., with all the ${ }^{56} \mathrm{Mn}$ within the film). In order to monitor the degree of disorder upon implantation of the radioactive probes and subsequent annealing, we also determined the lattice location of As using radioactive ${ }^{73} \mathrm{As}\left(t_{1 / 2}=80 \mathrm{~d}\right)$ in experiments $\mathrm{C}$ and $\mathrm{D}$. These experiments consisted of implanting a thin film as in experiment B with ${ }^{73}$ As to a fluence of $5 \times 10^{13} \mathrm{~cm}^{-2}$, with an energy of $50 \mathrm{keV}$ and an angle of $10^{\circ}$ (resulting in a peak concentration of $1.5 \times 10^{19} \mathrm{~cm}^{-3}$, a projected range of $26 \mathrm{~nm}$ and a straggling of $13 \mathrm{~nm}$, i.e., with all the ${ }^{73} \mathrm{As}$ within the film). Both ${ }^{56} \mathrm{Mn}$ and ${ }^{73} \mathrm{As}$ were implanted at room temperature, at the on-line isotope separator facility ISOLDE at CERN.
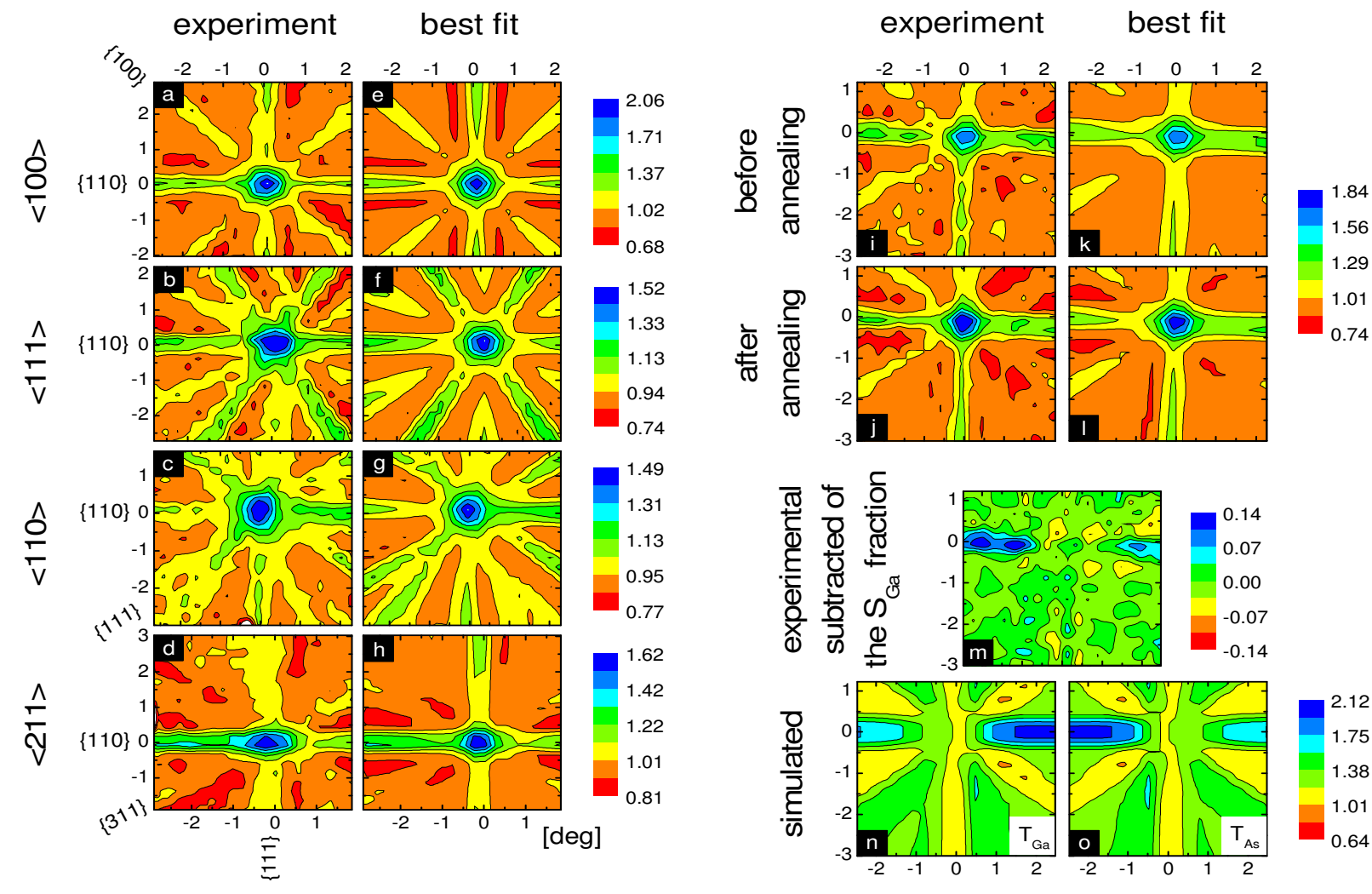

FIG. 1. (a)-(d) Experimental $\beta^{-}$emission patterns of experiment B after thermal annealing (10 min, in vacuum), along the four measured directions, and best fits of theoretical patterns (e)-(h). The best fit is obtained for $71 \%$ of the ${ }^{56} \mathrm{Mn}$ atoms on $\mathrm{S}_{\mathrm{Ga}}\left(\mathrm{Mn}_{s}\right)$ and $25 \%$ on $\mathrm{T}_{\mathrm{As}}$ $\left(\mathrm{Mn}_{i}\right)$ sites. (i) and (j) Experimental patterns and best fit (k) and (l) for experiment A (only the $<211>$ direction), before and after annealing ( $3 \mathrm{~h}$, in air). The best fits are obtained for $64 / 77 \%$ of the ${ }^{56} \mathrm{Mn}$ atoms on $\mathrm{S}_{\mathrm{Ga}}\left(\mathrm{Mn}_{s}\right)$ and $25 / 15 \%$ on $\mathrm{T}_{\mathrm{As}}\left(\mathrm{Mn}_{i}\right)$ sites before/after annealing. (m) Experimental pattern [of part (j)] after subtraction of the fitted $\mathrm{S}_{\mathrm{Ga}}$ component. (n) and (o) Simulated patterns for ${ }^{56} \mathrm{Mn}$ on $\mathrm{T}_{\mathrm{Ga}}$ and $\mathrm{T}_{\mathrm{As}}$ sites, respectively. 
Emission channeling measurements were carried out in the as-implanted state and after annealing at $200{ }^{\circ} \mathrm{C}$ : in air for $3 \mathrm{~h}$ in experiments $\mathrm{A}$ and $\mathrm{C}$; in vacuum $\left(<10^{-5} \mathrm{mbar}\right)$ for $10 \mathrm{~min}$ in experiments $\mathrm{B}$ and $\mathrm{D}$. Angular-dependent emission patterns were recorded along various crystallographic axis using a position- and energy-sensitive detection system similar to that described in Ref. 18. Experiments $\mathrm{A}$ and $\mathrm{B}$ (with relatively short-lived ${ }^{56} \mathrm{Mn}$ ) were performed on-line using the EC-SLI setup; ${ }^{19}$ experiments $\mathrm{C}$ and $\mathrm{D}$ (the longer-lived ${ }^{73} \mathrm{As}$ ) were performed off-line. ${ }^{18}$ In experiments $\mathrm{B}, \mathrm{C}$, and D, four axes were measured $(<100\rangle,<111\rangle,<110\rangle$, and $<211\rangle$ ), typical of emission channeling experiments on host semiconductors with cubic structure (cf. e.g., Refs. 14 and 15). In experiment A, the measurements were limited to the $<211>$ axis, which as will be shown below is sufficient to unambiguously determine the site occupancy (at least when combined with experiment $\mathrm{B}$, where all four axes were measured). The implantation parameters, film thickness, and annealing time of experiment A were carefully chosen to allow us to determine the lattice site(s) occupied by $\mathrm{Mn}_{i}$ in a stage of annealing for which the $\mathrm{Mn}_{i}$ fraction would have decreased to half of the as-grown/as-implanted value (based on magnetometry measurements). The theoretical emission patterns for probes occupying possible lattice sites are calculated using the many-beam formalism for electron channeling in single crystals. $^{20}$ The lattice location was quantitatively determined by fitting the experimental patterns with theoretical ones using the two-dimensional fit procedure outlined in Ref. 21. More details onto the experimental approach and data analysis, including a description of the lattice sites and how they can be unambiguously distinguished with emission channeling, can be found in Ref. 15. Other examples of emission channeling studies using short-lived isotopes of transition metals can be found in the following Refs. 22-24 for Mn, Refs. 23 and 25 for Co, and Refs. 19 and 26 for Ni.

As a representative example, Figs. 1(a)-1(h) show the experimental $\beta^{-}$emission patterns of experiment $\mathrm{B}$ after thermal annealing (10 min, in vacuum), along the four measured directions ((a)-(d)), as well as the best fits to the theoretical patterns ((e)-(h)). Similarly, Figs. 1(i)-1(l) compares experimental patterns ((i) and (j)) and best fit $((\mathrm{k})$ and (1)) for experiment A (only the <211> direction), both before and after annealing (3 h, in air). Fig. 1(m) qualitatively illustrate how the mirror asymmetry of the $\{110\}$-planar channeling measured in the vicinity of the $<211>$ direction (horizontal plane in the figure) allows us to distinguish between $\mathrm{T}_{\mathrm{As}}$ and $\mathrm{T}_{\mathrm{Ga}}$ sites: after subtracting from the experimental data the fitted component occupying substitutional $\mathrm{Ga}\left(\mathrm{S}_{\mathrm{Ga}}\right)$ sites, the asymmetry of the residual $\{110\}$-planar channeling corresponds to that of $\mathrm{T}_{\mathrm{As}}$, i.e., stronger channeling on the left versus right in Fig. 1(m), which is the opposite of $\mathrm{T}_{\mathrm{Ga}}$. Quantitative analysis is provided by numerically fitting the data to calculated patterns, as mentioned above, from which the fractions of ${ }^{56} \mathrm{Mn}$ atoms in the different lattice sites are obtained compiled in Fig. 2 (top) for experiments A and B. Figure 2 (bottom) illustrates the technique's sensitivity specifically for the case of $\mathrm{T}_{\mathrm{As}}$ versus $\mathrm{T}_{\mathrm{Ga}}$ occupancy, by showing for
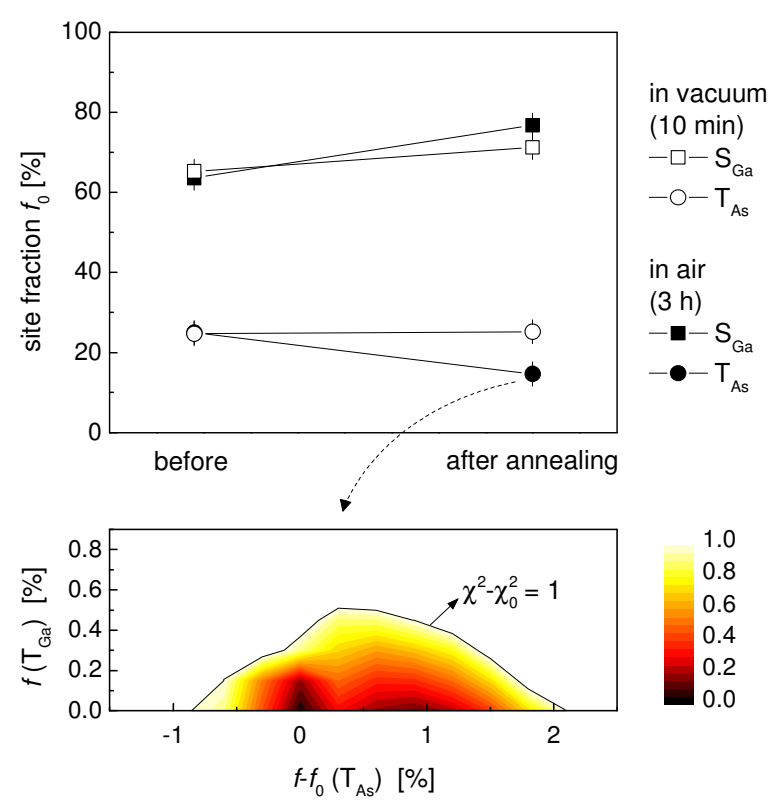

FIG. 2. Top: Fractions of ${ }^{56} \mathrm{Mn}$ atoms on $\mathrm{S}_{\mathrm{Ga}}$ and $\mathrm{T}_{\mathrm{As}}$ sites in experiments $\mathrm{A}$ and B. Bottom: Error associated with the fit $\chi^{2}-\chi_{0}^{2}$, with $\chi_{0}^{2}$ being the value for the best fit, for experiment $\mathrm{A}$ after annealing, as the fractions $f$ on $\mathrm{T}_{\mathrm{As}}$ and $\mathrm{T}_{\mathrm{Ga}}$ sites are varied in the vicinity of the best fit values $f_{0}\left(15 \%\right.$ for $\mathrm{T}_{\mathrm{As}}$ and $0 \%$ for $\left.\mathrm{T}_{\mathrm{Ga}}\right)$, leaving all other fit parameters free. The black line contour corresponds to $\chi^{2}-\chi_{0}^{2}=1$.

experiment $\mathrm{A}$ (after annealing) the error associated with the fit $\left(\chi^{2}\right)$ as the fractions on $\mathrm{T}_{\mathrm{As}}$ and $\mathrm{T}_{\mathrm{Ga}}$ sites are varied in the vicinity of the best fit values $\left(15 \%\right.$ for $\mathrm{T}_{\mathrm{As}}$ and $0 \%$ for $\mathrm{T}_{\mathrm{Ga}}$, with $\chi_{0}^{2}$ ), leaving all other fit parameters free. The black line contour corresponds to $\chi^{2}-\chi_{0}^{2}=1$, giving standard deviations of $2 \%$ for the $\mathrm{T}_{\mathrm{As}}$ fraction and of $0.5 \%$ for $\mathrm{T}_{\mathrm{Ga}}$. Note that the percentages are with respect to all the ${ }^{56} \mathrm{Mn}$, i.e., even if there is indeed $\mathrm{T}_{\mathrm{Ga}}$ occupancy within the techniques sensitivity, it is for all purposes negligible. Vanishing $\mathrm{T}_{\mathrm{Ga}}$ occupancy (with comparable standard deviation) is found both before and after annealing, both in experiments $\mathrm{A}$ and $\mathrm{B}$.

Before discussing in detail the $T_{A s}$ versus $T_{G a}$ occupancy, we make three relevant observations. First, while the interstitial $\mathrm{Mn}$ fraction is unaffected by the $10 \mathrm{~min}$ vacuum annealing (experiment B), annealing for $3 \mathrm{~h}$ in air decreases it by almost a factor of 2 . This is consistent with our complementary magnetometry measurements (cf. supplementary material ${ }^{27}$ ), and with the $\mathrm{Mn}_{i}$ annealing kinetics previously reported based on transport and magnetometry measurements. ${ }^{3,28}$ Second, in both experiments $\mathrm{A}$ and $\mathrm{B}$, we observe an increase in substitutional fraction upon annealing, which we attribute to the recovery of disordered regions (created upon implantation), rather than interstitial $\mathrm{Mn}$ being converted to substitutional. This is confirmed by experiments C and D, where we see a comparable increase of the substitutional As fractions (cf. supplementary material ${ }^{27}$ ). Third, it is important to note that the determined site-fractions correspond to the implanted radioactive ${ }^{56} \mathrm{Mn}$ probes, which are not necessarily (and most likely are not) the same as 


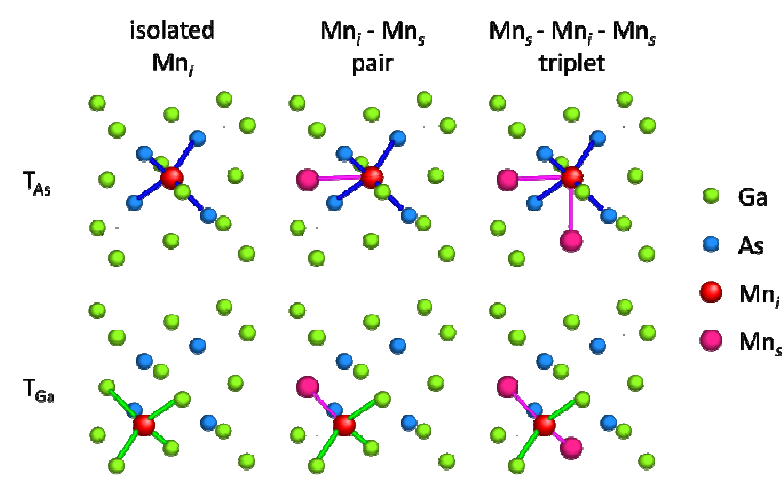

FIG. 3. Representation of the relevant $\mathrm{Mn}_{\mathrm{i}}$ sites and coordination: in $\mathrm{T}_{\mathrm{As}}$ (top) and $\mathrm{T}_{\mathrm{Ga}}$ (bottom) sites, for isolated $\mathrm{Mn}_{i}, \mathrm{Mn}_{i}-\mathrm{Mn}_{s}$ pairs, and $\mathrm{Mn}_{s}-\mathrm{Mn}_{i}-\mathrm{Mn}_{s}$ triplets. Our data show that regardless of the coordination, $\mathrm{Mn}_{i}$ always occupies $\mathrm{T}_{\mathrm{As}}$ sites (top).

those of the stable ${ }^{55} \mathrm{Mn}$ atoms incorporated during MBE growth. The goal of these experiments was not to determine the absolute fraction of interstitial $\mathrm{Mn}$ in $(\mathrm{Ga}, \mathrm{Mn}) \mathrm{As}$, but to evaluate the stability of the possibly occupied interstitial sites, which we discuss next.

The main finding here is that interstitial Mn occupies only $\mathrm{T}_{\mathrm{As}}$ sites, with negligible (if any) $\mathrm{T}_{\mathrm{Ga}}$ occupancy. In terms of the local structure of $\mathrm{Mn}_{i}$ (in $\mathrm{T}_{\mathrm{As}}$ sites), there are essentially three possible situations to consider (Fig. 3): isolated $\mathrm{Mn}_{i}$ (coordinated by $\mathrm{As}$ and $\mathrm{Ga}$ in the first and second neighbor shell), $\mathrm{Mn}_{i}-\mathrm{Mn}_{s}$ pairs (with a $\mathrm{Mn}_{s}$ substituting one of the $\mathrm{Ga}$ atoms in the second neighbor shell), and $\mathrm{Mn}_{s}-\mathrm{Mn}_{i}-\mathrm{Mn}_{s}$ triplets (with two $\mathrm{Mn}_{s}$ substituting $\mathrm{Ga}$ atoms in the second neighbor shell). The effect of larger complexes (e.g., $3 \mathrm{Mn}_{s}-\mathrm{Mn}_{i}$ ) can be neglected since the fraction of substitutional $\mathrm{Mn}$ in such configurations is significantly smaller than those considered $\left(11 \%\right.$ for $3 \mathrm{Mn}_{s}$ and even smaller for larger complexes, assuming random Mn distribution). ${ }^{29}$ The thermal stability, i.e., the activation energy for diffusion $E_{\mathrm{a}}$, increases from isolated $\mathrm{Mn}$ to $\mathrm{Mn}_{i^{-}}$ $\mathrm{Mn}_{\mathrm{s}}$ pairs to $\mathrm{Mn}_{s}-\mathrm{Mn}_{i}-\mathrm{Mn}_{s}$ triplets: ${ }^{13} E_{\mathrm{a}}=E_{\mathrm{m}}$ for isolated $\mathrm{Mn}$, with $E_{\mathrm{m}}$ being the effective migration barrier in a $\mathrm{T}_{\mathrm{As}^{-}}$ $\mathrm{T}_{\mathrm{Ga}}-\mathrm{T}_{\mathrm{As}}$ path; $E_{\mathrm{a}}=E_{\mathrm{m}}+E_{\mathrm{b}}$ for $\mathrm{Mn}_{i}-\mathrm{Mn}_{s}$ pairs and $\mathrm{Mn}_{s}-\mathrm{Mn}_{i^{-}}$ $\mathrm{Mn}_{s}$ triplets, with $E_{\mathrm{b}}$ being the binding energy of the complexes, which is larger for $\mathrm{Mn}_{s}-\mathrm{Mn}_{i}-\mathrm{Mn}_{s}$ triplets due to the Coulomb interaction between ionized $\mathrm{Mn}_{i}$ donors and $\mathrm{Mn}_{s}$ acceptors (one/two $\mathrm{Mn}_{s}$ for pairs/triplets). Since the ${ }^{56} \mathrm{Mn}$ probes are randomly distributed upon implantation, and long range diffusion of $\mathrm{Mn}_{s}$ and $\mathrm{Mn}_{i}$ is suppressed at room temperature, we can expect the largest fraction of isolated $\mathrm{Mn}_{i}$ in the as-implanted state. At $200{ }^{\circ} \mathrm{C}, \mathrm{Mn}_{i}$ is mobile and, therefore, isolated $\mathrm{Mn}_{i}$ and $\mathrm{Mn}_{i}$ in $\mathrm{Mn}_{i}-\mathrm{Mn}_{s}$ pairs progressively populate the $\mathrm{Mn}_{s}-\mathrm{Mn}_{i}-\mathrm{Mn}_{s}$ configuration (with the dissociation of $\mathrm{Mn}_{i}$ from $\mathrm{Mn}_{s}-\mathrm{Mn}_{i}-\mathrm{Mn}_{s}$ triplets being the limiting reaction for long-range diffusion of $\mathrm{Mn}_{i}$ ). Since we observe vanishing $\mathrm{T}_{\mathrm{Ga}}$ occupancy both before and after annealing, we can conclude that the $\mathrm{T}_{\mathrm{As}}$ site is the most stable site regardless of $\mathrm{Mn}_{i}$ being isolated, in $\mathrm{Mn}_{i}-\mathrm{Mn}_{s}$ pairs or in $\mathrm{Mn}_{s}-\mathrm{Mn}_{i}-\mathrm{Mn}_{s}$ triplets. In other words, regardless of the $\mathrm{Mn}_{s}$ coordination, the migration path of $\mathrm{Mn}_{i}$ between neighboring $\mathrm{T}_{\mathrm{As}}$ and $\mathrm{T}_{\mathrm{Ga}}$ sites is asymmetric, with $\mathrm{T}_{\mathrm{As}}$ being the lower energy side. This picture is in qualitative agreement with previous ab initio calculations for the different coordination configurations. ${ }^{13}$ An experimental assessment of the different energy barriers at play requires a detailed investigation of the lattice location as a function of annealing temperature. We are currently carrying out such studies.

$\mathrm{T}_{\mathrm{As}}$ occupancy is consistent with the expectation of having the Mn cations (substitutional as well as interstitial) coordinated by As anions rather than Ga cations. For $\mathrm{Mn}_{i^{-}}$ $\mathrm{Mn}_{s}$ complexes, however, one could expect the Coulomb attraction between oppositely charged $\mathrm{Mn}_{s}$ acceptors and $\mathrm{Mn}_{i}$ donors to counteract the repulsion between positively charged $\mathrm{Mn}_{i}$ and $\mathrm{Ga}$ cations, making the $\mathrm{T}_{\mathrm{Ga}}$ site energetically more favorable. More specifically, since the distance between neighboring $\mathrm{S}_{\mathrm{Ga}}$ and $\mathrm{T}_{\mathrm{Ga}}$ sites $(2.45 \AA)$ is smaller than that between neighboring $\mathrm{SGa}$ and TAs sites (2.83 $\AA$ ), the decrease in Coulomb energy by decreasing the $\mathrm{Mn}_{s}-\mathrm{Mn}_{i}$ distance (from $\mathrm{T}_{\mathrm{As}}$ to $\mathrm{T}_{\mathrm{Ga}}$ ) could eventually counteract the increase in energy of changing the Mni coordination from As to Ga cations. However, our results show that even if this occurs, the gain in energy associated with having the $\mathrm{Mn}_{i}$ cations coordinated by As anions is still the dominant factor, irrespective of the Coulomb interaction in $\mathrm{Mn}_{i}-\mathrm{Mn}_{s}$ complexes.

In summary, we have shown that the interstitial Mn occupies only $\mathrm{T}_{\mathrm{As}}$ sites both before and after thermal annealing at $200{ }^{\circ} \mathrm{C}$, which implies that $\mathrm{T}_{\mathrm{As}}$ is the energetically favorable site regardless of the interstitial $\mathrm{Mn}$ atom being isolated or forming complexes with substitutional $\mathrm{Mn}$. These results solve the long standing controversy regarding $T_{\mathrm{As}}$ versus $\mathrm{T}_{\mathrm{Ga}}$ occupancy, thus contributing to the understanding of electric and magnetic self-compensation in (Ga,Mn)As.

This work was supported by the Fund for Scientific Research-Flanders, the Concerted Research Action of the KU Leuven GOA/14/007, the KU Leuven BOF (CREA/14/013 and STRT/14/002), the Portuguese Foundation for Science and Technology (CERN/FP/123585/2011), the BMBF German research program under Contract Nos. 05KK7TS2 and 05K10TS2 G.N.P.O., and the European Union Seventh Framework through ENSAR (European Nuclear Science and Applications Research, Contract No. 262010) and SPIRIT (Support of Public and Industrial Research Using Ion Beam Technology, Contract No. 227012).

${ }^{1}$ T. Dietl and H. Ohno, Rev. Mod. Phys. 86, 187 (2014).

${ }^{2}$ T. Dietl, Nat. Mater. 9, 965 (2010).

${ }^{3}$ T. Jungwirth, K. Wang, J. Mašek, K. Edmonds, J. König, J. Sinova, M. Polini, N. Goncharuk, A. MacDonald, M. Sawicki, A. Rushforth, R. Campion, L. Zhao, C. Foxon, and B. Gallagher, Phys. Rev. B 72, 165204 (2005).

${ }^{4}$ M. Dobrowolska, K. Tivakornsasithorn, X. Liu, J. K. Furdyna, M. Berciu, K. M. Yu, and W. Walukiewicz, Nat. Mater. 11, 444 (2012).

${ }^{5}$ M. Wang, K. Edmonds, B. Gallagher, A. Rushforth, O. Makarovsky, A. Patanè, R. Campion, C. Foxon, V. Novak, and T. Jungwirth, Phys. Rev. B 87, 121301 (2013).

${ }^{6}$ K. Yu, W. Walukiewicz, T. Wojtowicz, I. Kuryliszyn, X. Liu, Y. Sasaki, and J. Furdyna, Phys. Rev. B 65, 201303 (2002).

${ }^{7}$ F. Glas, G. Patriarche, L. Largeau, and A. Lemaître, Phys. Rev. Lett. 93, 086107 (2004). 
${ }^{8}$ A. Wolska, K. Lawniczak-Jablonska, M. Klepka, R. Jakiela, J. Sadowski, I. Demchenko, E. Holub-Krappe, A. Persson, and D. Arvanitis, Acta Phys. Pol. A 114, 357 (2008).

${ }^{9}$ K. Lawniczak-Jablonska, J. Libera, A. Wolska, M. Klepka, R. Jakiela, and J. Sadowski, Radiat. Phys. Chem. 78, S80 (2009).

${ }^{10}$ V. Holy, X. Marti, L. Horak, O. Caha, V. Novak, M. Cukr, and T. U. Schulli, Appl. Phys. Lett. 97, 181913 (2010).

${ }^{11}$ L. Horák, Z. Sobá, and V. Holý, J. Phys.: Condens. Matter 22, 296009 (2010).

${ }^{12}$ T.-L. Lee, C. Bihler, W. Schoch, W. Limmer, J. Daeubler, S. Thieß, M. S. Brandt, and J. Zegenhagen, Phys. Rev. B 81, 235207 (2010).

${ }^{13}$ V. Baykov, P. Korzhavyi, and B. Johansson, Phys. Rev. Lett. 101, 177204 (2008).

${ }^{14}$ L. M. C. Pereira, U. Wahl, S. Decoster, J. G. Correia, M. R. da Silva, A. Vantomme, and J. P. Araujo, Appl. Phys. Lett. 98, 201905 (2011).

${ }^{15}$ L. M. C. Pereira, U. Wahl, S. Decoster, J. G. Correia, L. M. Amorim, M. R. da Silva, J. P. Araújo, and A. Vantomme, Phys. Rev. B 86, 125206 (2012).

${ }^{16}$ R. Campion, K. Edmonds, L. Zhao, K. Wang, C. Foxon, B. Gallagher, and C. Staddon, J. Cryst. Growth 251, 311 (2003).

${ }^{17}$ J. F. Ziegler, J. P. Biersack, and M. D. Ziegler, SRIM, the stopping and range of ions in matter (Lulu Press, Maryland, USA, 2009).

${ }^{18}$ U. Wahl, J. Correia, A. Czermak, S. Jahn, P. Jalocha, J. Marques, A. Rudge, F. Schopper, J. Soares, A. Vantomme, and P. Weilhammer, Nucl. Instrum. Methods Phys. Res., Sect. A 524, 245 (2004).

${ }^{19}$ M. R. Silva, U. Wahl, J. G. Correia, L. M. Amorim, and L. M. C. Pereira, Rev. Sci. Instrum. 84, 073506 (2013).

${ }^{20}$ H. Hofsäss and G. Lindner, Phys. Rep. 201, 121 (1991).

${ }^{21}$ U. Wahl, J. Correia, S. Cardoso, J. Marques, A. Vantomme, and G. Langouche, Nucl. Instrum. Methods Phys. Res., Sect. B 136-138, 744 (1998).

${ }^{22}$ S. Decoster, S. Cottenier, U. Wahl, J. G. Correia, L. M. C. Pereira, C. Lacasta, M. R. Da Silva, and A. Vantomme, Appl. Phys. Lett. 97, 151914 (2010).

${ }^{23}$ L. M. C. Pereira, U. Wahl, S. Decoster, J. Correia, L. Amorim, M. da Silva, J. Araújo, and A. Vantomme, Phys. Rev. B 84, 125204 (2011).

${ }^{24}$ L. M. C. Pereira, U. Wahl, J. G. Correia, S. Decoster, L. M. Amorim, M. R. da Silva, J. P. Araújo, and A. Vantomme, Phys. Rev. B 86, 195202 (2012).

${ }^{25}$ L. M. C. Pereira, U. Wahl, J. G. Correia, L. M. Amorim, D. J. Silva, S. Decoster, M. R. da Silva, K. Temst, and A. Vantomme, Nucl. Instrum. Methods Phys. Res., Sect. B 143, 332 (2014).

${ }^{26}$ L. M. C. Pereira, U. Wahl, J. G. Correia, L. Amorim, D. Silva, E. Bosne, S. Decoster, M. da Silva, K. Temst, and A. Vantomme, Appl. Phys. Lett. 103, 091905 (2013).

${ }^{27}$ See supplementary material at http://dx.doi.org/10.1063/1.4905556 for ${ }^{73} \mathrm{As}$ emission channeling (experiments $\mathrm{C}$ and $\mathrm{D}$ ) and magnetic characterization.

${ }^{28}$ K. Edmonds, P. Bogusawski, K. Wang, R. Campion, S. Novikov, N. Farley, B. Gallagher, C. Foxon, M. Sawicki, T. Dietl, M. Buongiorno Nardelli, and J. Bernholc, Phys. Rev. Lett. 92, 037201 (2004).

${ }^{29}$ R. E. Behringer, J. Chem. Phys. 29, 537 (1958). 